Research Article

\title{
Evaluating RLWT Rutting Test of Asphalt Mixtures Based on Industrial Computerized Tomography
}

\author{
Wenliang Wu (D), Zhi Li (D), Xiaoning Zhang (D), and Minghui Li (iD \\ School of Civil Engineering and Transportation, South China University of Technology, Guangzhou 510640, China \\ Correspondence should be addressed to Zhi Li; 41548915@qq.com
}

Received 11 October 2017; Revised 21 March 2018; Accepted 5 May 2018; Published 24 June 2018

Academic Editor: Giorgio Pia

Copyright (C) 2018 Wenliang Wu et al. This is an open access article distributed under the Creative Commons Attribution License, which permits unrestricted use, distribution, and reproduction in any medium, provided the original work is properly cited.

To eliminate the effects of image's light and shade difference when separating and distinguishing the material composition, a method is put forward, namely, ring-type and partitions threshold segmentation. It means setting up different segment threshold for different areas of the same image and then combining these different areas into one image. Furthermore, by analyzing the CT image before and after the RLWT rutting test for the drilling specimen and Marshall specimen and taking the volume of air voids and the angle (alpha) between max main axis and $X$ axis, the differences of two kinds of specimens' macrotest results were discussed from internal structure distribution. Here, we show that there are differences between macrotest results of two kinds of specimens because of internal air voids and aggregate distribution, which should be considered for compliance testing.

\section{Introduction}

With the increasing traffic volume and the effects of heavy-duty axle loading, pavement rutting has become one of major distresses occurring in asphalt pavements. It can influence the safety and the driving comfort directly when the rutting depth reaches a certain limit [1]. A variety of methods, such as French Pavement Rutting Tester (PRT), Hamburg Wheel-Tracking Device (WTD), Asphalt Pavement Analyzer (APA), and Rotary Loaded Wheel Tester (RLWT), have been used for estimating the rutting performance of the asphalt concrete pavement in the world. The Rotary Loaded Wheel Tester, developed in the US in the late 1990s, has been paid more and more attention because of its convenience and ease of use. It can evaluate the rutting performance by measuring the mixture sample and pavement coring specimens whose diameter is $100 \mathrm{~mm}$ or $150 \mathrm{~mm}$. The further study on quality control conformance testing about applying RLWT to asphalt pavement has begun $[2,3]$.

As a unique nondestructive evaluation technique, industrial computerized tomography (CT) can inspect the reaction of material interior structures dynamically and quantificationally and provide a new method to researching interior structures. The computer-aided design of asphalt mixtures based on industrial CT, a prospective technology, is predicted as "the next generation of infrastructure materials research" and "analysis modeling and design method based on system." Masad used CT to research asphalt mixture very early, and he paid more attention to the volumetric properties, contact relationship, and numerical simulation $[4,5]$. Wang et al. have done some research on 3D reconstruction technology and performed a large number of numerical simulation test based on $3 \mathrm{D}$ reconstruction technology $[6,7]$. The author's team researched the CT technology for asphalt mixture and made certain progress [8]. The main challenge of CT technology is that the brightness of CT image varies according to the distance with central axis because of the low ray power of industrial $\mathrm{CT}$ machine. And the $\mathrm{CT}$ image cannot give obvious peak, and this challenge leads to some problems in distinguishing different materials accurately.

Based on the foregoing background, this paper developed a new method to segment threshold, namely, ringtype and partitions threshold segmentation. This means setting up different segment thresholds for different areas of the same image and then combining these different areas into one image. Furthermore, by analyzing the CT image 
before and after the RLWT rutting test for pavement core and indoor specimen and taking the volume of air voids and the angle alpha between max main axis and $X$ axis, the differences of two kinds of specimens' macrotest results were discussed from internal structure distribution.

\section{Ring-Type and Partitions Threshold Segmentation}

Threshold segmentation is one way to distinguish the voids, asphalt mastic, and aggregates through segmenting images, whose accuracy largely depend on the selection of threshold T1 and T2 [9]. Many researchers take the 2-mode method to analyze the images. This way can generate threshold by applying point correlation technique, assuming that the image between the two peaks is the same medium and preliminarily determining the threshold $\mathrm{T} 1$ and $\mathrm{T} 2$ and then ascertaining the $\mathrm{T} 1$ and $\mathrm{T} 2$ by trial and error. However, after carefully comparing the slice images of different positions scanned by CT, it can be found that the gray level information of each image is not consistent completely, and the gray value of the same kind of material scanned in different position is not same. The gray level information of single image cannot generally represent the whole sample distributing disciplinarian. In addition, from the original image scanned by CT (Figure 1), it can be found that the surrounding of the image is darker than that in the center. Figure 2 shows the image which is consisted by the gray value $189-255$ of pixel points. And, it can be seen from Figure 2 that the aggregate around the image can be roughly distinguished, but the one in the center is not clear. The threshold segmentation uses gray value to distinguish the material. Therefore, it is very necessary to adjust image so that the same material can be in the same gray level. Ring-type and partitions threshold segmentation helps to solve this problem.

In view of nonuniformity that the gray value of the same material in the CT image gradually increases from the center to the edge, the CT image is divided into different ring-type images. The specific steps are as follows: (1) dividing the whole image into a series of overlapping by $50 \%$ ring-type subimage (the center image is round.); (2) using Otsu's method [10] for each subimage to calculate the gray threshold of the aggregate and the background; (3) finally, combining the sub-image processed in step 2.

The following is an example about the application of the ring-type and partitions threshold segmentation when the number of the ring is five.

(1) The first step is dividing the whole image into five subimages and dealing with image uniformity processing separately. The result is shown in Figure 3.

(2) Then establishing the gray histogram of each subimage (as is shown in Figure 4). Table 1 shows gray value statistics of the subimage.

Finally, the appropriate image segmentation algorithm is selected (Otsu's method is selected in this article), and each subimage is segmented. Then, the aggregate particles are

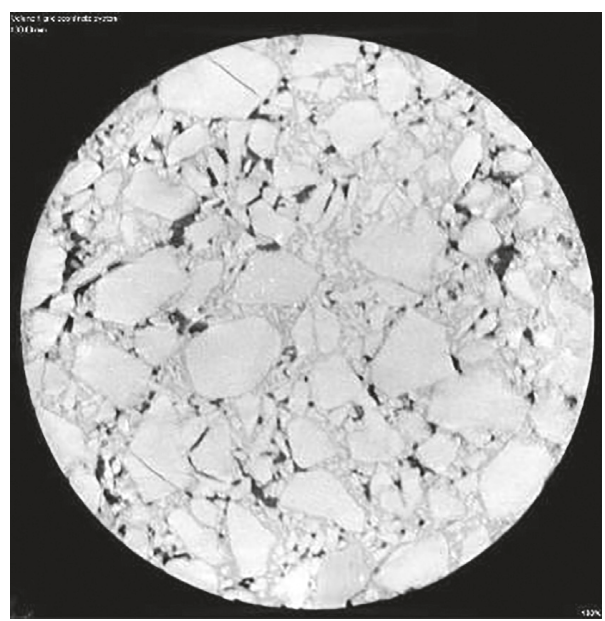

Figure 1: Original image of CT scanning.

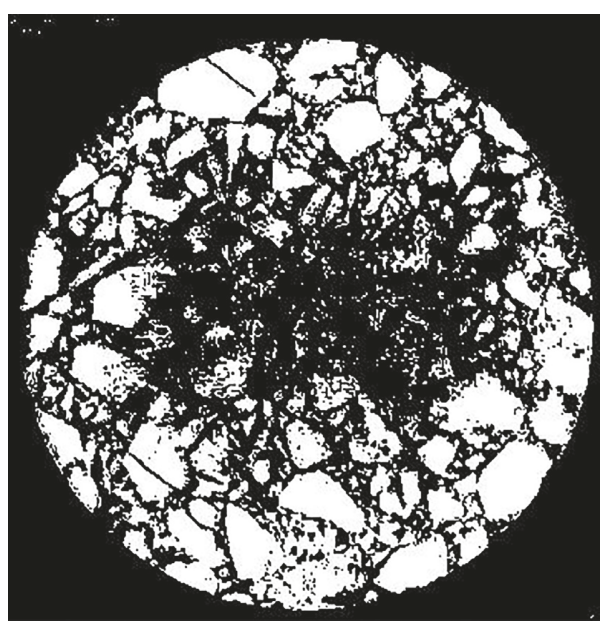

FIgURE 2: Image of gray level from 189 to 245.

isolated and the subimages are combined, which only contains aggregate particles. Figure 5 shows the final aggregate image.

This article has attempted other normal methods (fuzzy c-mean method, GMM-EM method, and otsu method) to analyze the CT image, as shown in Figures 6-8. From Figures 5 and 8, it is shown that using ring-type and partitions threshold segmentation method is much better to extracting aggregates than segmenting the image directly. Furthermore, a normal method requires human interaction, and its efficiency is low with the specimen's radius growing. Ring-type and partitions threshold segmentation is a method of variable threshold processing and can solve the problem of uneven background since lowenergy X-ray.

The ring-type and partitions threshold segmentation method is suitable for situation that the gray of the same material is changing gradually from the center to the edge in CT image. For poor quality images, the quality of image segmentation can be improved by appropriately increasing the number of rings. 


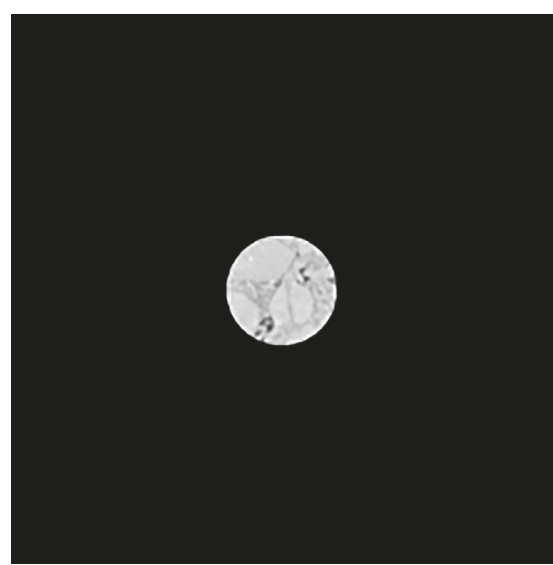

(a)

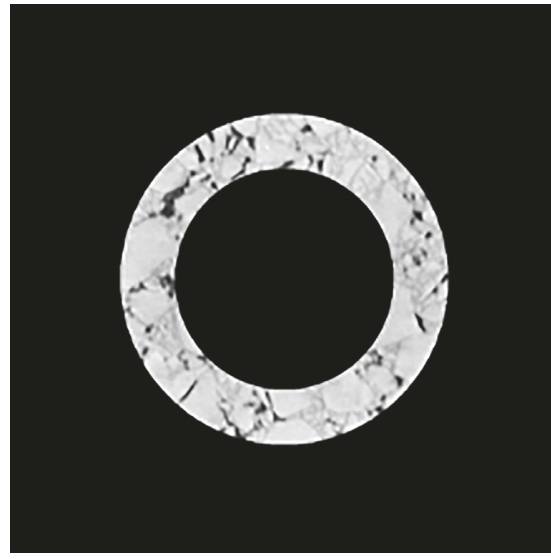

(c)

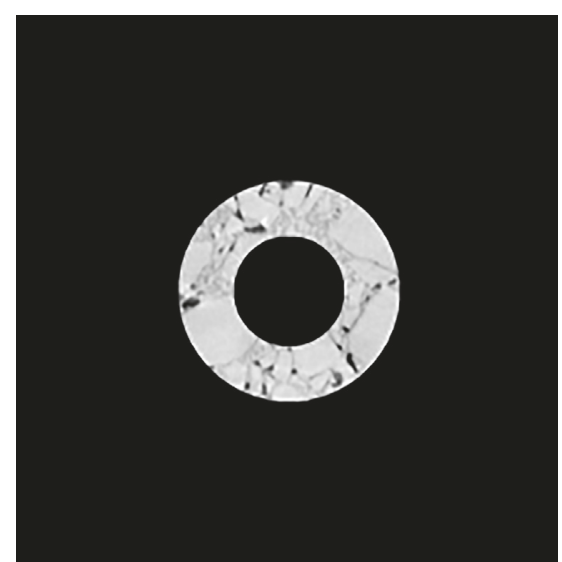

(b)

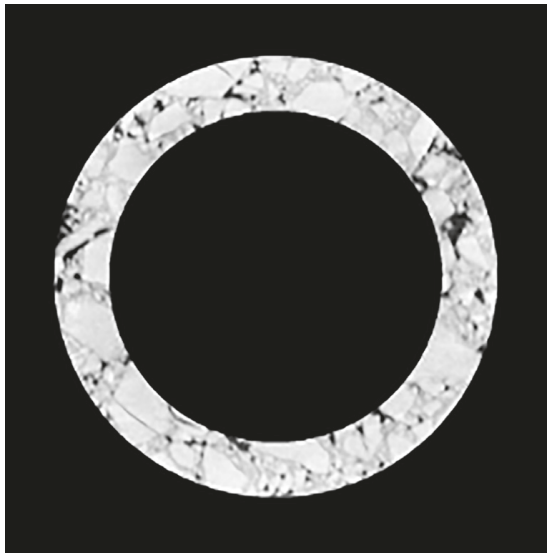

(d)

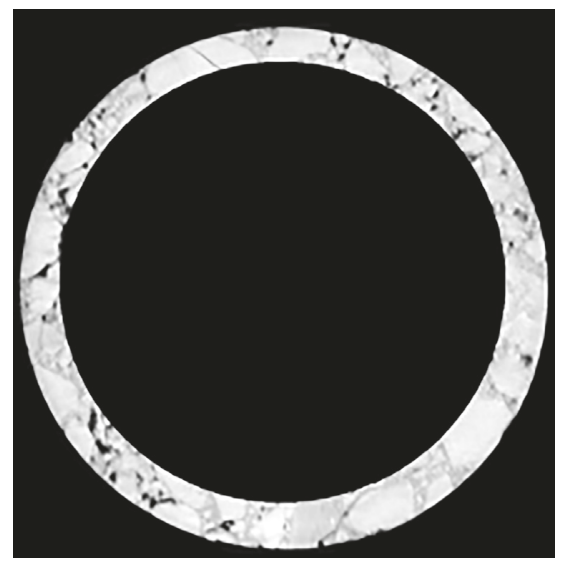

(e)

FIGURE 3: Subimage after segmentation: (a) central disk, (b) second ring, (c) third ring, (d) fourth ring, and (e) fifth ring.

\section{RLWT Rutting Test}

RLWT is a one direction device with no horizontal displacement, as shown in Figure 9. Figure 10 shows the stress pattern of the specimen. There are ten small rubber wheels arranged at the edge of a big rotary wheel. When the shaft spins once, every rubber wheel will load the specimen once. In this test, a 125 Newton force and $0.7 \mathrm{MPa}$ contact pressure is applied to the surface of the specimen through freespinning rubber wheel. Most of the sample will be tested over 16,000 load application. Besides, it will test and record rut depth and the corresponding loading time automatically. And the maximum rut depth of the test is $6.35 \mathrm{~mm}$, and the maximum loading number is 60,000 .

\section{Summary and Discussion}

Drilling three core samples is performed in the middle layer of AC-20 asphalt pavement. Table 2 presents the gradation of 


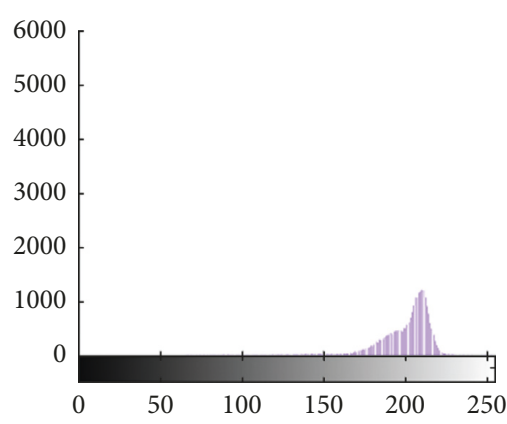

(a)

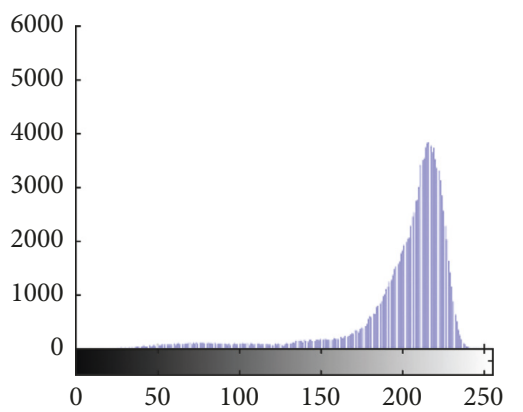

(c)

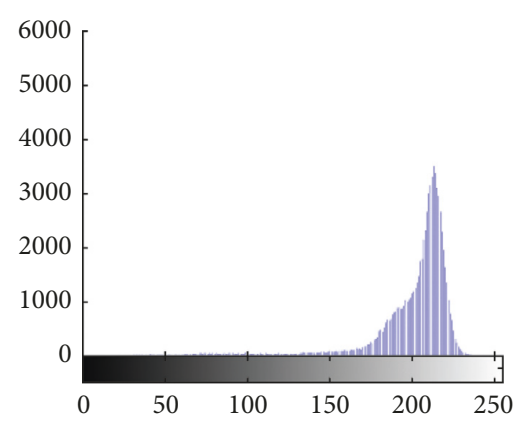

(b)

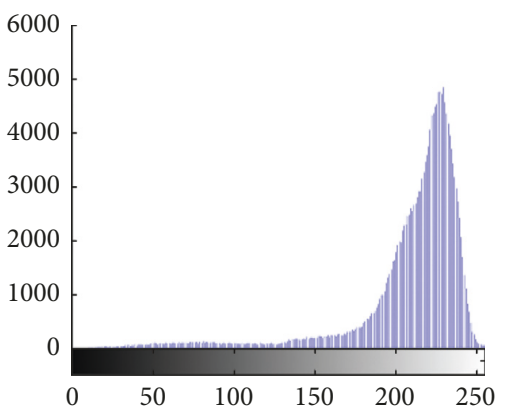

(d)

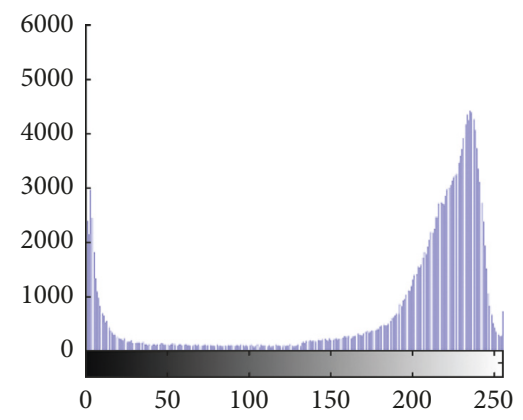

(e)

FIGURE 4: Gray histogram of the subimage: (a) central disk, (b) second ring, (c) third ring, (d) fourth ring, and (e) fifth ring.

TABLE 1: Statistical table of gray level.

\begin{tabular}{lccccc}
\hline Subimage & Statistical starting point & Statistical end point & Peak value & Average & Standard deviation \\
\hline Central disk & 158 & 233 & 211 & 202 & 6.86 \\
Second ring & 128 & 240 & 214 & 204 & 7.78 \\
Third ring & 121 & 244 & 217 & 206 & 9.26 \\
Fourth ring & 116 & 255 & 230 & 215 & 2.63 \\
Fifth ring & 114 & 255 & 236 & 218 & 10 \\
\hline
\end{tabular}

AC-20 asphalt mixtures. Scanning the two kinds of the sample before and after the RLWT and processing the CT image.

4.1. Void Ratio Distribution Characteristics. The specimen's study area is chosen after scanning, eliminating the effect of external drop shadow, and determining the void segment threshold value $\mathrm{T} 1$ by trial method. The air void is assumed to be the part of the specimen, whose gray value between 0 and
T1, as shown in Figure 11. Furthermore, the air voids content can be measured by the image method through calculating the ratio of the volume of void against the total volume of the specimen. Table 3 presents the specimen's air voids.

From Table 2, it can be found that the range of void is very wide. And the air void contents of the in-place sample's variability are much greater than those of the Marshall specimen. The air void content measured by the image method is less than the one measured by the standard method, and the latter is about 1.2 times of the former. The 


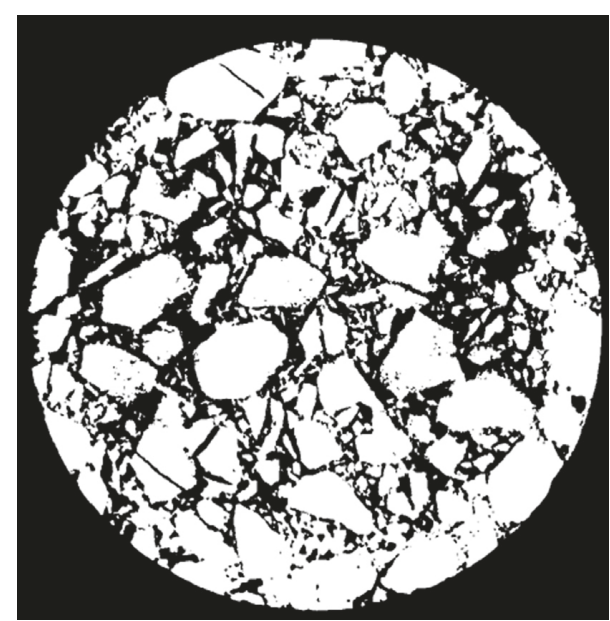

FIgURE 5: Aggregate image after segmentation.

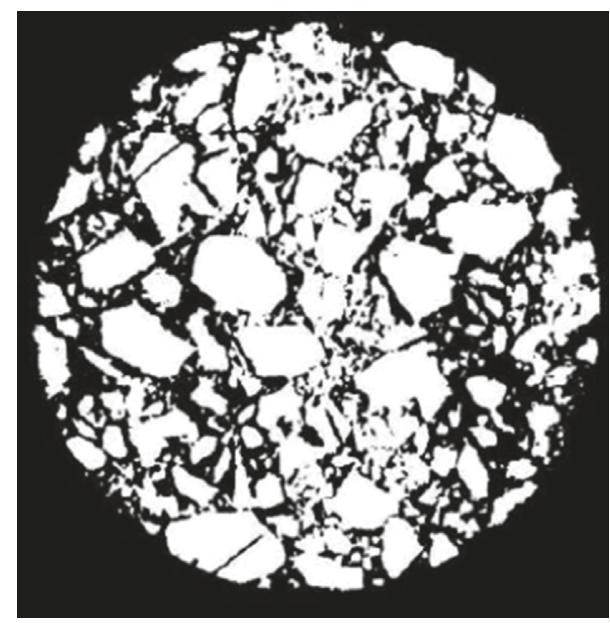

Figure 6: Fuzzy c-mean method.

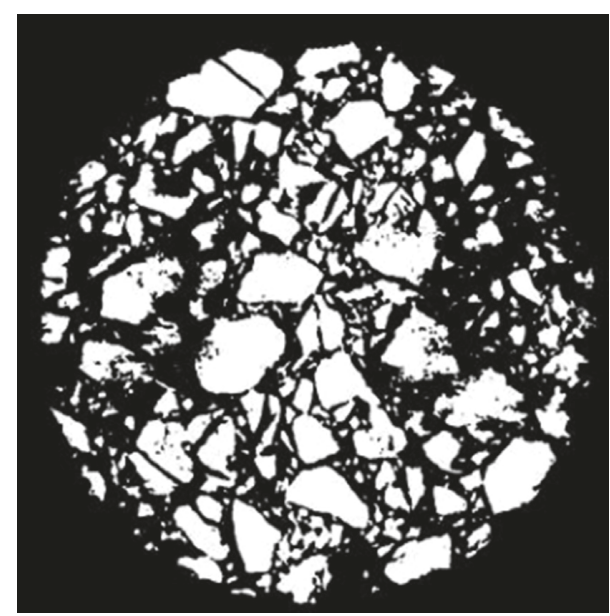

Figure 7: GMM-EM method.

reason is that some small pores cannot be identified because of the relationship of the image quality and the program application adaptability. Another important reason is that

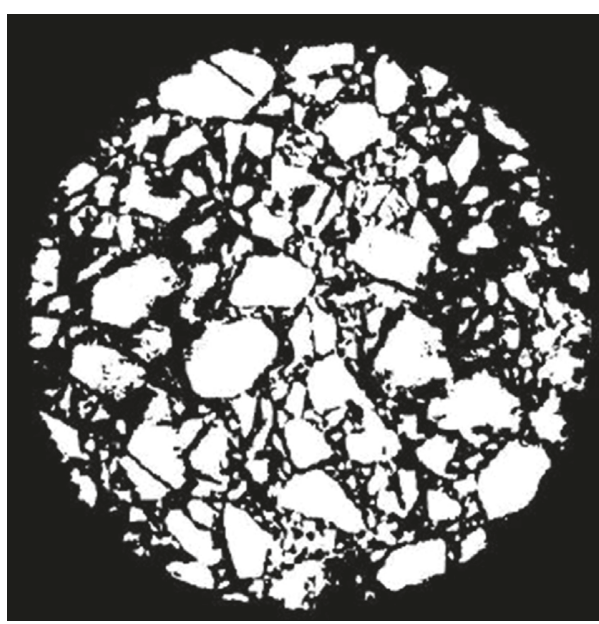

FIGURE 8: Otsu method.

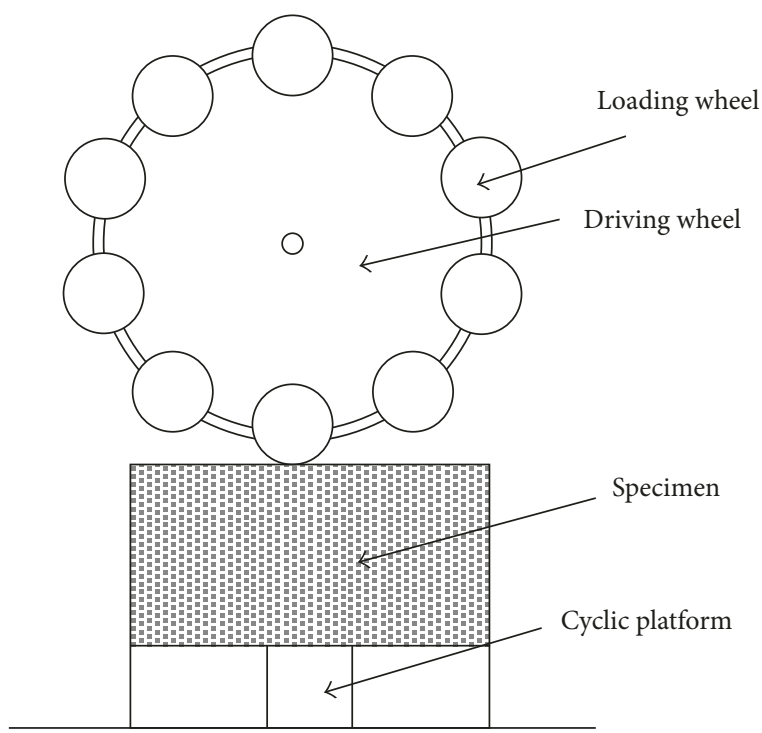

FIGURE 9: Loading sketch of RLWT.

the open pore is processed as part of background in the image processing. After analyzing upper $3 \mathrm{~mm}$ air void of the sample, it can be found that the upper air void of the in-place sample is $5.5 \%$, but the sample shaped in laboratory is only $4.09 \%$. The difference of the upper air void directly led to the sample's performance difference. When the pavement compaction degree is low, also means the initial void is high, the aggregate particles cannot interlock very well with each other, and the contact point is unstable. Besides, the compaction rutting might occur under the dynamic loading because of lacking bearing capacity.

4.2. Aggregate Particles Distribution Characteristics. For the line connecting two points on the edge of aggregate particles, there is a unique longest line called particle's main axis, and the main axis intersects the edge of the aggregate particles at the endpoints. The direction of the particle axis, represented by alpha $\left(0 \leq\right.$ alpha $\left.\leq 90^{\circ}\right)$, is the angle between the particle axis and the $X$ axis. The physical meaning of it is shown in Figure 12 [11]. 


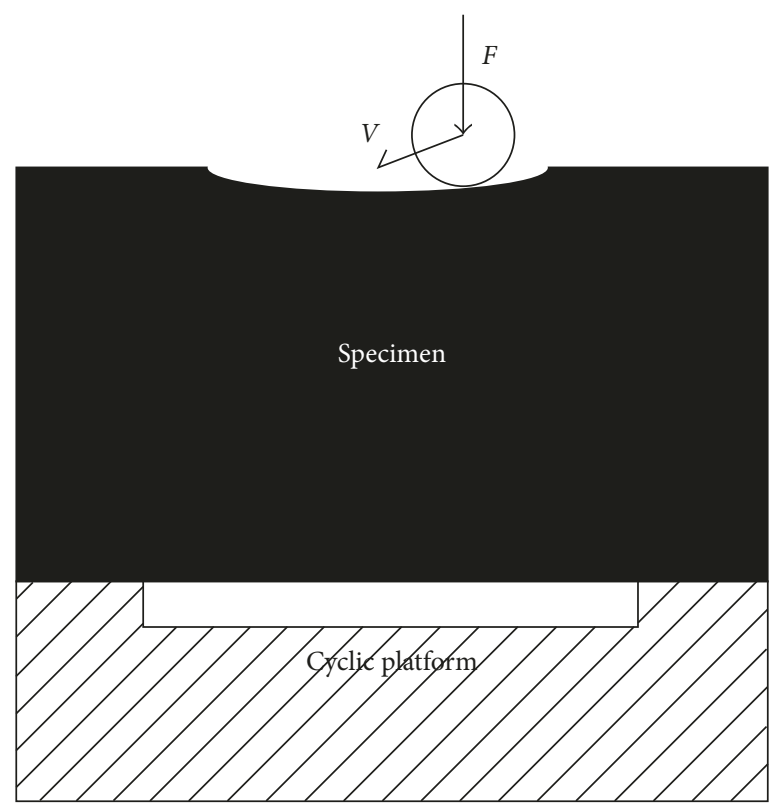

FIGURE 10: Stress pattern of specimen.

TABLE 2: Gradation of AC-20 asphalt mixtures.

\begin{tabular}{lccccccccccccc}
\hline \multirow{2}{*}{ Gradation $(\mathrm{mm})$} & \multicolumn{10}{c}{ Percent passing } \\
& 26.5 & 19 & 16 & 13.2 & 9.5 & 4.75 & 2.36 & 1.18 & 0.6 & 0.3 & 0.15 & 0.075 & Asphalt-aggregate ratio (\%) \\
\hline AC-20 & 100 & 94.9 & 84.8 & 73.3 & 54.4 & 34.8 & 22.1 & 18.5 & 14.5 & 11.3 & 9.0 & 5.4 & 4.2 \\
\hline
\end{tabular}

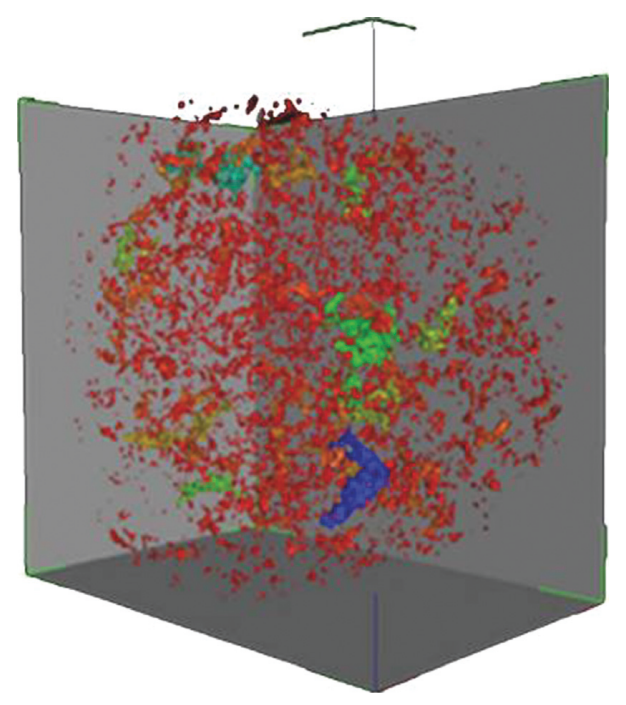

Figure 11: 3D image of air voids.

According to the research of Chen and Liao [12], there is a good correlation between the direction of the particle axis and rutting resistance performance of mixture. Therefore, dividing the coarse aggregate into three types is based on the direction of particle axis: (1) the aggregate whose alpha is in $0^{\circ} \sim 30^{\circ}$ is regraded as stable aggregate because of low center of gravity, (2) the aggregate whose alpha is in $30^{\circ} \sim 60^{\circ}$ may become unstable because of higher center of gravity, and (3) the aggregate whose alpha is in $31^{\circ} \sim 60^{\circ}$ is unstable. It is easy for angle change to appear and lead to pavement rutting.
TABLe 3: Statistical table of air void ratio.

\begin{tabular}{lccc}
\hline Item & $\begin{array}{c}\text { Drilling } \\
\text { specimen }\end{array}$ & $\begin{array}{c}\text { Marshall } \\
\text { specimen }\end{array}$ \\
\hline & $\begin{array}{c}\text { Threshold } T_{1} \\
\text { Air void content of upper } \\
\text { 3 mm specimen (\%) }\end{array}$ & 40 & 40 \\
& Air void content (\%) & 3.50 & 4.09 \\
Image & Maximum air void & 6.55 & 3.0 \\
method & $\quad \begin{array}{c}\text { content (\%) } \\
\text { Minimum air void content (\%) } \\
\text { Variable coefficient }\end{array}$ & 2.5 & 1.6 \\
& $\begin{array}{c}\text { Standard air void content (\%) } \\
\text { (submerged weight in water } \\
\text { method) }\end{array}$ & 0.33 & 0.28 \\
& $\quad 4.71$ & 3.53 \\
\hline
\end{tabular}

While researching the distribution characteristics of aggregate particles, the CT image of the samples needs to be obtained first, followed by applying the ring-type and partitions threshold segmentation method (the CT image is shown in Figure 13(a)). Finally, testing the specimens 16,000 times and scanning the specimens at the same location should be performed. The aggregate particles image is shown in Figure 13(b). Figure 14 shows the relation between deformation and loading times. The alpha is counted before and after the rutting test in these 9 images. And the statistical method is used to analyze the change of alpha before and after the rutting test. The result is shown in Table 4 .

It can be found from Figure 11 that the deformation of the drilling specimen is significantly larger than laboratory 


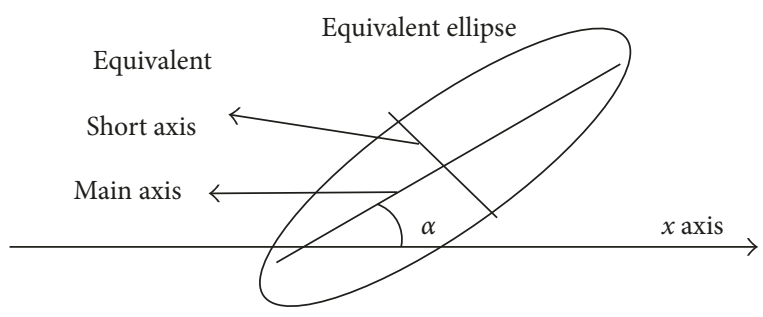

Figure 12: Particles' orientation of main axis.

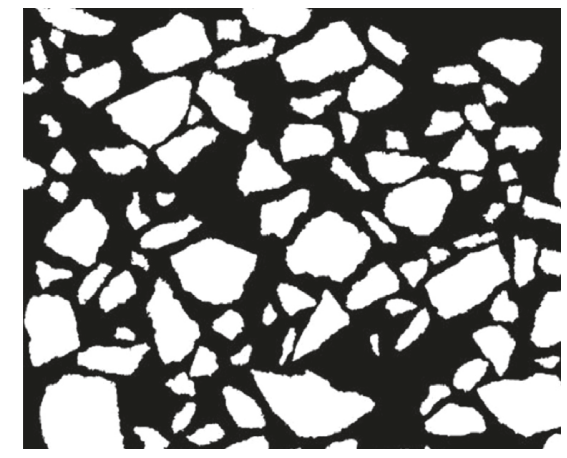

(a)

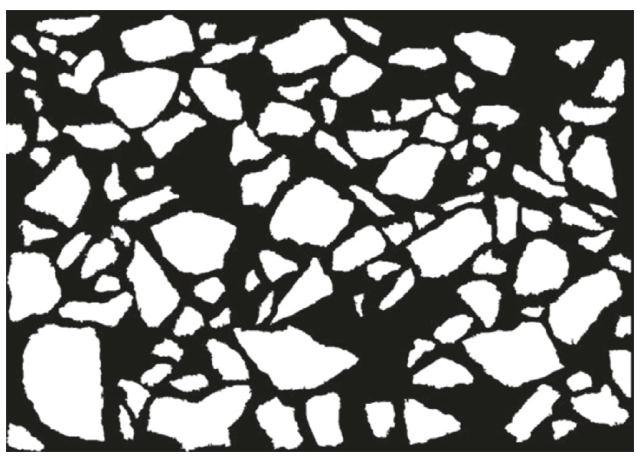

(b)

Figure 13: (a) Aggregate particles before the rutting test; (b) aggregate particles after the rutting test.

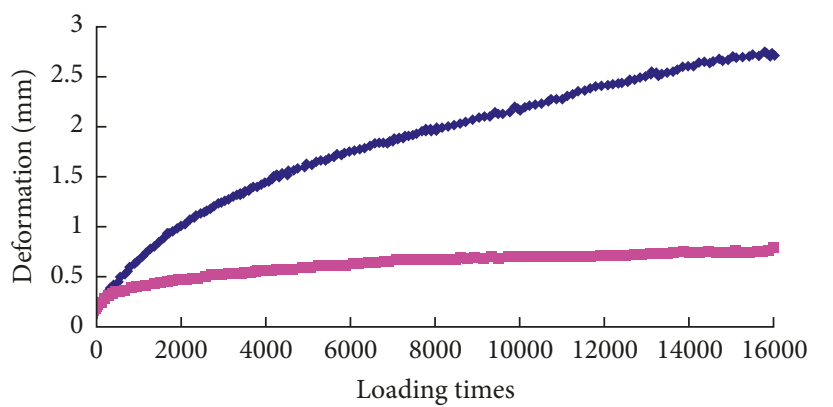

- Drilling specimen

- Marshall specimen

Figure 14: Relation between deformation and loading times.

Marshall specimen deformation. This is mainly due to the impact of the rolling method and construction factors. And it causes the larger air void contents of the drilling specimen,
TABLE 4: Statistical table of alpha.

\begin{tabular}{|c|c|c|c|c|c|}
\hline \multirow{2}{*}{$\begin{array}{l}\text { Specimen } \\
\text { type }\end{array}$} & \multirow[t]{2}{*}{ Aggregate size } & \multicolumn{3}{|c|}{$\begin{array}{c}\text { The proportion of } \\
\text { alpha (\%) }\end{array}$} & \multirow{2}{*}{$\begin{array}{l}\text { Average } \\
\text { angle }\left({ }^{\circ}\right)\end{array}$} \\
\hline & & $0^{\circ} \sim 30^{\circ}$ & $31^{\circ} \sim 60^{\circ}$ & $61^{\circ} \sim 90^{\circ}$ & \\
\hline \multirow{3}{*}{$\begin{array}{l}\text { Drilling } \\
\text { specimen } \\
\text { before the } \\
\text { rutting test }\end{array}$} & $2.36 \sim 4.75 \mathrm{~mm}$ & 46 & 34 & 20 & 35.83 \\
\hline & $4.75 \sim 9.5 \mathrm{~mm}$ & 69 & 16 & 15 & 29.60 \\
\hline & $9.5 \sim 20 \mathrm{~mm}$ & 62 & 19 & 19 & 27.08 \\
\hline \multirow{3}{*}{$\begin{array}{l}\text { Drilling } \\
\text { specimen } \\
\text { after the } \\
\text { rutting test }\end{array}$} & $2.36 \sim 4.75 \mathrm{~mm}$ & 51 & 30 & 19 & 37.79 \\
\hline & $4.75 \sim 9.5 \mathrm{~mm}$ & 66 & 24 & 10 & 28.86 \\
\hline & $9.5 \sim 20 \mathrm{~mm}$ & 67 & 22 & 11 & 25.00 \\
\hline \multirow{3}{*}{$\begin{array}{l}\text { Marshall } \\
\text { specimen } \\
\text { before the } \\
\text { rutting test }\end{array}$} & $2.36 \sim 4.75 \mathrm{~mm}$ & 44 & 28 & 28 & 39.87 \\
\hline & $4.75 \sim 9.5 \mathrm{~mm}$ & 54 & 29 & 17 & 39.59 \\
\hline & $9.5 \sim 20 \mathrm{~mm}$ & 47 & 30 & 23 & 43.98 \\
\hline \multirow{3}{*}{$\begin{array}{l}\text { Marshall } \\
\text { specimen } \\
\text { after the } \\
\text { rutting test }\end{array}$} & $2.36 \sim 4.75 \mathrm{~mm}$ & 47 & 26 & 27 & 40.61 \\
\hline & $4.75 \sim 9.5 \mathrm{~mm}$ & 41 & 34 & 25 & 38.92 \\
\hline & $9.5 \sim 20 \mathrm{~mm}$ & 33 & 50 & 17 & 40.01 \\
\hline
\end{tabular}

especially in the upper specimen. Therefore, drilling the core sample easily causes compactness rutting because of its higher porosity.

From Table 4, it can be found that the specimen is not only vertically compressed, but also affected by the shear stress because the base of rotary loaded wheel tester is suspended. And the shear effort is obvious, especially when the specimen is thin. The average alpha value of the drilling specimen and the laboratory Marshall specimen is $31^{\circ} \sim 60^{\circ}$. It indicates that both of the specimens under different shaping methods might convert from an unstable condition into stable condition. From the variance of alpha value before and after the rutting test, it can be found that the alpha of aggregate decreases gradually after the rutting test. The particle proportion of alpha in $61^{\circ} \sim 90^{\circ}$ decrease significantly, while the one in $31^{\circ} \sim 60^{\circ}$ increases evidently, and it changes a little in $0^{\circ} \sim 30^{\circ}$ range. In other words, the specimen obtains higher stability after being tested by RLWT.

The variation of aggregate particles' alpha mainly occurred in the coarse aggregate (the size over $4.75 \mathrm{~mm}$ ), especially the part of large particle (over $9.5 \mathrm{~mm}$ ). But the alpha of fine aggregate particle changes insignificantly compared with the change of coarse aggregate particles. The change of large particles are mainly due to the conversion of $61^{\circ} \sim 90^{\circ}$ aggregate particles into $31^{\circ} \sim 60^{\circ}$ aggregate particles. The average alpha value of $2.36 \sim 4.75 \mathrm{~mm}$ aggregate particles increases after being tested by RLWT, while the average alpha value of coarse aggregate particles decreases.

Comparing the $0^{\circ} \sim 30^{\circ}$ aggregate particles' proportion between the drilling specimen and the Marshall specimen in $0^{\circ} \sim 30^{\circ}$ range, it can be found that the value of the drilling specimen is larger. Which means conversion ratio of the drilling specimen from unstable condition to stable condition is relatively small. When compared with the $31^{\circ} \sim 90^{\circ}$ of large particle proportion, the proportion of the Marshall specimen is larger. In other words, the Marshall specimen has higher possibility of converting into an unstable condition. It also means that the large particle of the Marshall 
specimen has larger rotation under loading. Comparing the $0^{\circ} \sim 30^{\circ}$ aggregate particles' proportion between the drilling specimen and the Marshall specimen in $0^{\circ} \sim 30^{\circ}$ range, it can be found that the value of the drilling specimen is larger. Which means conversion ratio of the drilling specimen from the unstable condition to stable condition is relatively small. When compared with the $31^{\circ} \sim 90^{\circ}$ of large particle proportion, the proportion of the Marshall specimen is larger. In other words, the Marshall specimen has higher possibility of converting into the unstable condition. It also means that the large particle of the Marshall specimen has larger rotation under loading.

\section{Conclusions}

(1) In view of the situation that the gray of the same material changes gradually from the center to the edge in CT image, applying ring-type and partitions threshold segmentation method is better for the result and more accurate for particles extraction when compared with segmenting the whole image directly.

(2) The air void variability of the drilling core is higher than that of the Marshall specimen. The air void value measured by the image method is less than the one measured by the standard method. And the later is about 1.2 times of the former. The air void of drilling core within the $3 \mathrm{~mm}$ upper specimen is far more than that of the Marshall specimen. The difference of upper air void will make the difference of the specimen performance directly.

(3) After RLWT rutting test, it can be found that the alpha value of the drilling specimen and the Marshall specimen decreases, and the specimens convert from unstable condition into stable condition. But the change of each shift aggregate is different. What is more, the alpha change of the two kinds of specimens is different because of the shaping method.

(4) The two kinds of specimens, whose volumetric properties and mix proportions are same, have different internal material (void and aggregate particle) distribution, macroscopic volume parameters, and mechanics indexes because of the different shaping method. It should be paid more attention when we do compliance test of construction quality.

\section{Conflicts of Interest}

The authors declare that they have no conflicts of interest.

\section{Acknowledgments}

The work represented herein was the result of a team effort. The authors acknowledge the support of the National Natural Science Foundation of China (Grant nos. 51008131 and 51038004).

\section{References}

[1] X. N. Zhang, Quality Control and Assure of Asphalt Pavement Construction, China Communications Press, Beijing, China, 2009.

[2] H. Lu, L. L. Hu, and X. N. Zhang, "Influence of asphalt mixture interior factors on RLWT test," Highway, vol. 10, pp. 204-207, 2009.

[3] J. Xu, S. C. Huang, Y. C. Qin et al., "Mixes design for rut-filling micro-surfacing trials," Petroleum Asphalt, vol. 24, no. 2, pp. 25-29, 2010.

[4] E. Mahmoud and E. Masad, "Experimental methods for the evaluation of aggregate resistance to polishing, abrasion, and breakage," Journal of Materials in Civil Engineering, vol. 19, no. 1, pp. 977-985, 2007.

[5] E. Masad, A. Al Omari, and H. C. Chen, "Computations of permeability tensor coefficients and anisotropy of asphalt concrete based on microstructure simulation of fluid flow," Computational Materials Science, vol. 40, no. 4, pp. 449-459, 2007.

[6] L. B. Wang, X. Wang, L. Mohammad, and Y. Wang, "Application of mixture theory in the evaluation of mechanical properties of asphalt concrete," Journal of Materials in Civil Engineering, vol. 16, no. 2, pp. 167-174, 2004.

[7] L. B. Wang, J. D. Frost, L. Mohammad et al., ThreeDimensional Aggregate Evaluation Using X-Ray Tomography Imaging, Transportation Research Board (TRB), Washington, DC, USA, 2002.

[8] X. N. Zhang, "Basic methods of digital image technology for material structure of asphalt mixtures," Journal of South China University of Technology, vol. 40, no. 10, pp. 166-173, 2012.

[9] X. J. Li, J. F. Zhang, K. N. Liu et al., "Finite element modeling of geomaterial using digital image processing and computerized tomography identification," Roch and Soil Mechanics, vol. 27, no. 8, pp. 1331-1334, 2006.

[10] X. N. Zhang, Y. H. Duan, Z. Li et al., "Classification of asphalt mixture materials based on X-ray computed tomography," Journal of South China University of Technology, vol. 38, no. 10, pp. 120-124, 2011.

[11] Z. Li, Analysis of Volume Constituent Characteristics for Asphalt Mixture Based on Digital Image Processing, Harbin Institute of Technology, Harbin, China, 2002.

[12] J.-S. Chen and M.-C. Liao, "Evaluation of internal resistance in hot-mix asphalt (HMA) concrete," Construction and Building Materials, vol. 16, no. 6, pp. 313-319, 2002. 


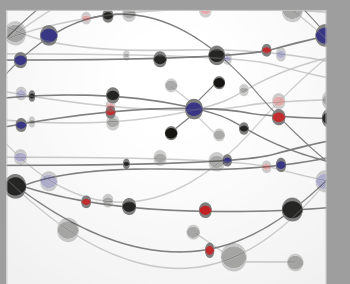

The Scientific World Journal
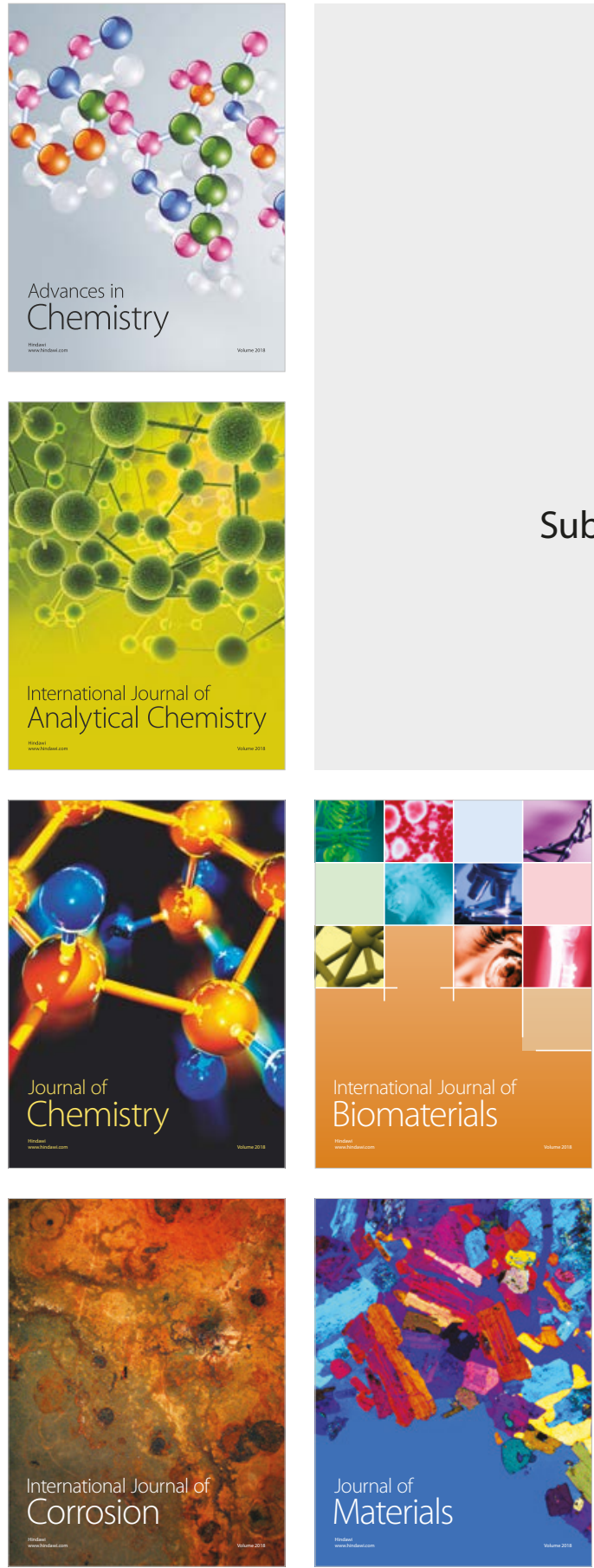

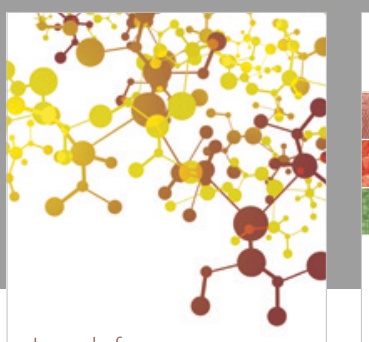

Journal of

Applied Chemistry
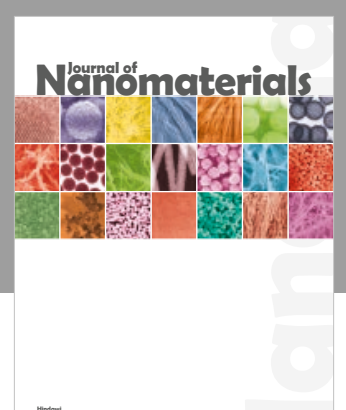

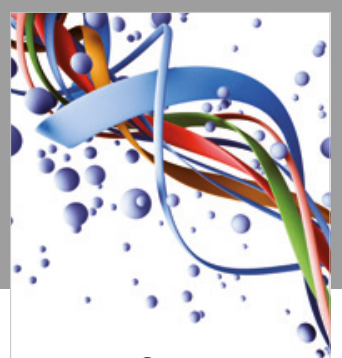

Scientifica

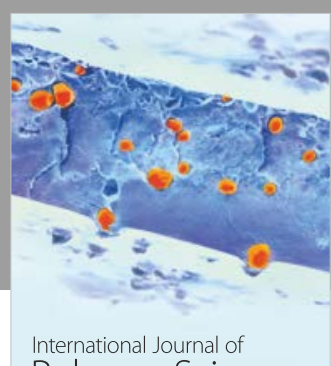

Polymer Science

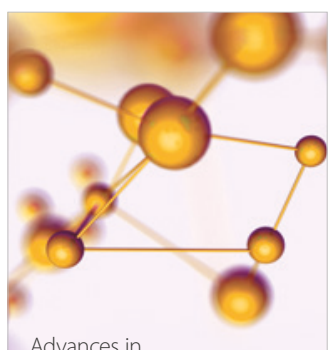

Physical Chemistry
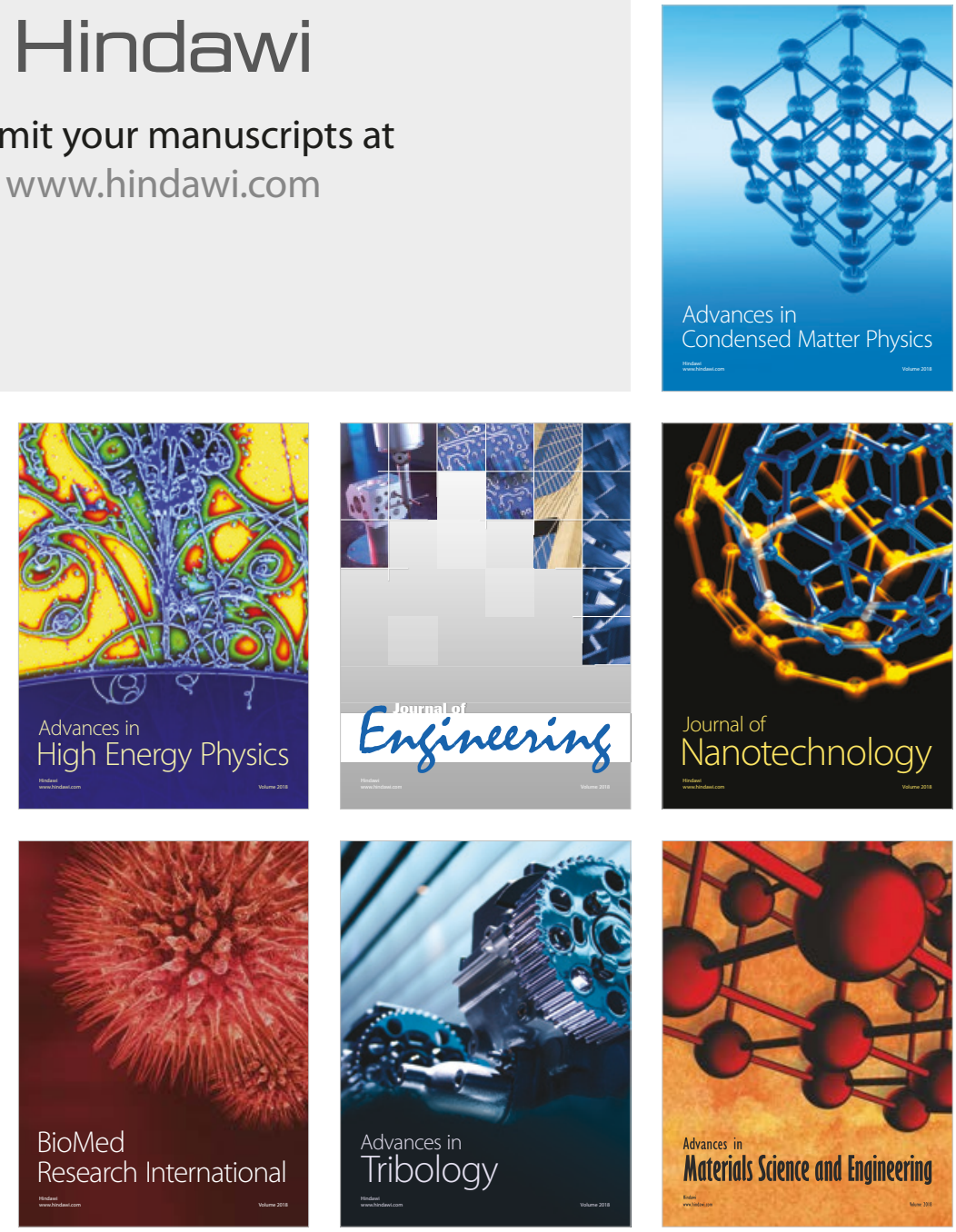